\title{
ANALYSIS OF POWER CONVERTER LOSSES IN VECTOR CONTROL SYSTEM OF A SELF-EXCITED INDUCTION GENERATOR
}

\author{
Mateo Bašić — Dinko Vukadinović — Miljenko Polić ${ }^{*}$
}

\begin{abstract}
This paper provides analysis of losses in the hysteresis-driven three-phase power converter with IGBTs and free-wheeling diodes. The converter under consideration is part of the self-excited induction generator (SEIG) vector control system. For the analysis, the SEIG vector control system is used in which the induction generator iron losses are taken into account. The power converter losses are determined by using a suitable loss estimation algorithm reported in literature. The chosen algorithm allows the power converter losses to be determined both by type (switching/conduction losses) and by converter component (IGBT/diode losses). The overall power converter losses are determined over wide ranges of rotor speed, dc-link voltage and load resistance, and subsequently used for offline correction of the overall control system's losses (efficiency) obtained through control system simulations with an ideal power converter. The control system's efficiency values obtained after the correction are compared with the measured values.
\end{abstract}

K e y w ords: self-excited induction generator, vector control, converter losses, hysteresis switching, efficiency

\section{INTRODUCTION}

Induction generators, especially the squirrel-cage type, have several significant advantages over other types of electric generators, such as the conventional synchronous generator [1]. In particular, they have the capability to excite without an external reactive power source as well as to generate power over a wide range of rotor speeds, which led to their increased application in stand-alone power generating systems of power up to $15 \mathrm{~kW}$ [2]. The self-excitation of a squirrel-cage induction generator has been known since the 1930s [3, 4]. In its most basic form, the self-excitation is achieved by means of a fixed capacitor bank connected across the stator terminals of an induction generator, provided that the rotor is rotating with appropriate speed. The main disadvantage of such approach is that both the frequency and magnitude of the generated voltage are highly dependent on the rotor speed, the excitation capacitance, the machine's parameters and both the value and power factor of the connected load. Hence, if constant generated voltage is to be achieved and maintained, the excitation capacitance needs to be adjusted with respect to the rotor speed and connected load. Today, this is mainly achieved by using vector control systems in which the self-excited induction generator (SEIG) is excited by means of a single capacitor combined with a power converter. The basic configuration of such system is shown in Fig. 1. It has to be noted, however, that only the rapid development of the microcontroller technology and high-speed semiconductor devices such is the insulated-gate bipolar transistor (IGBT) since the mid-1980s has made possible the effective application of the vector control principles to induction machines.
In most SEIG vector control systems reported in literature certain power losses are, for the sake of convenience, neglected during the development of the corresponding control algorithm and also omitted from the control system's model. These losses can be divided into prime mover losses, induction machine losses (iron losses, stray losses, and friction and windage losses) and power converter losses. Because these losses exist in the actual system, not taking them into account leads, at the very least, to overestimation of the actual system's efficiency. In general, to determine how well the model estimates the actual system's losses, it is necessary to compare the losses obtained through simulations with the losses obtained by measurements. For the system shown in Fig. 1, when the total input power is measured at the induction machine's rotor, as is usually the case, then the prime mover losses are not included in the power balance equation of the system and may well be omitted from the corresponding model. However, all other above mentioned losses take place somewhere between the induction machine's rotor (input power measurement point) and the electric load (output power measurement point) so they should be taken into consideration when estimating the system's losses or efficiency. In [5-7], it is shown that if the SEIG iron losses are omitted from the corresponding model, its efficiency is likely to be substantially overestimated. Moreover, in [7], it is shown that by omitting the iron losses from the SEIG vector control algorithm, highly reliable vector control cannot be achieved and detuning is likely to take place. Hence, to obtain an accurate SEIG model and to achieve satisfactory control, the iron losses should be included both in the SEIG model and in the control algorithm. On the other hand, the stray losses and the mechanical losses (friction and windage) contribute

* University of Split, Faculty of Electrical Engineering, Mechanical Engineering and Naval Architecture R. Boškovića 32, 21000 Split, Croatia, mabasic@fesb.hr,dvukad@fesb.hr, mipolic@fesb.hr 


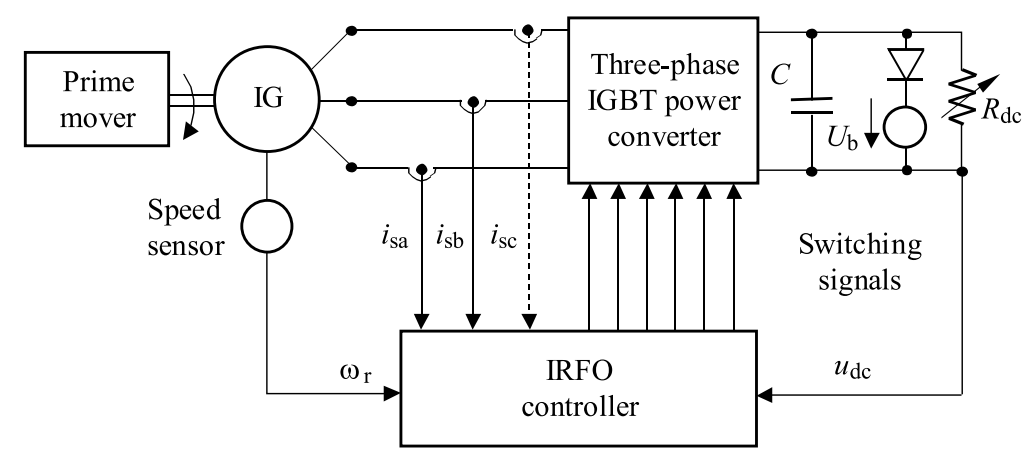

Fig. 1. Basic configuration of the SEIG control system

to a lesser extent to the overall induction machine losses compared to the iron losses, especially when the induction machine is lightly loaded or operating with the rotor speeds lower than the rated speed. Even at rated conditions, the stray and mechanical losses only amount to about $3 \%$ of the rated power $[8,9]$, while the iron losses alone can exceed $7 \%$ of the rated power $[6,7]$. As for the power converter losses, they have not yet been properly dealt with in the context of a vector controlled SEIG, especially for the case of aperiodic switching schemes, such as the hysteresis switching, which are not uncommon in induction machine vector control systems. Hence, the contribution of the power converter losses in such systems is yet to be determined. This represents the main objective of this paper.
Most available power converter loss estimation methods assume a fixed switching frequency [10-14]. Loss estimation methods based on thermal measurements, although applicable regardless of the switching scheme, require knowledge of thermal resistances and installation of thermocouples, which is usually expensive and inconvenient [15-18]. Model-based method presented in [19] requires detailed knowledge of the IGBT and diode physical structure and involves extensive simulations, while methods presented in $[20,21]$ are device-specific and require applying a similar procedure to an IGBT-diode pair when different gate-drive circuits, dc-link voltage and junction temperatures are of interest. The methods presented in [22-26] have the potential for extension to aperiodic switching, but have only been tested for periodic switching. A simple and promising method for estimat-

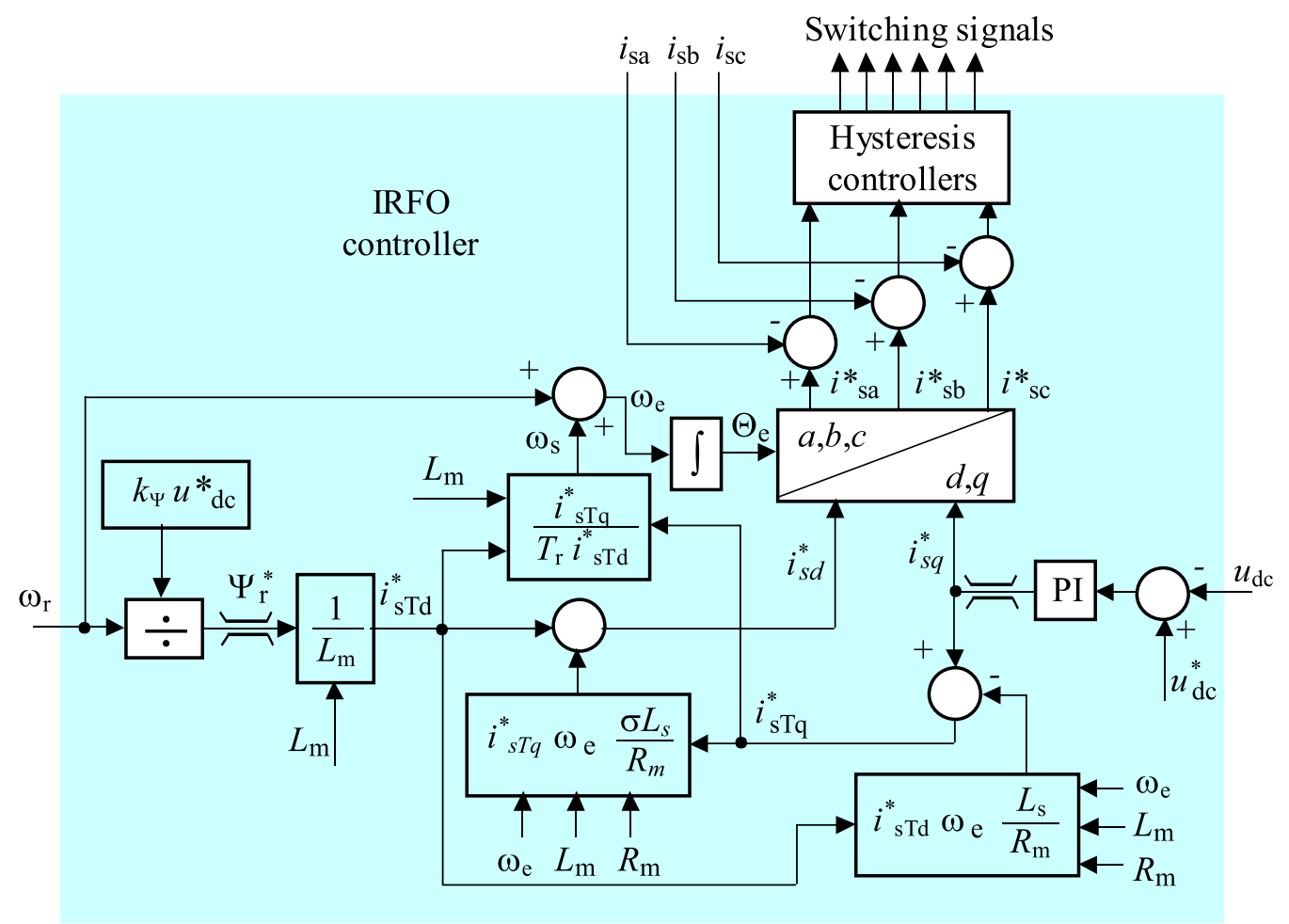

Fig. 2. Indirect rotor-field-oriented controller scheme 


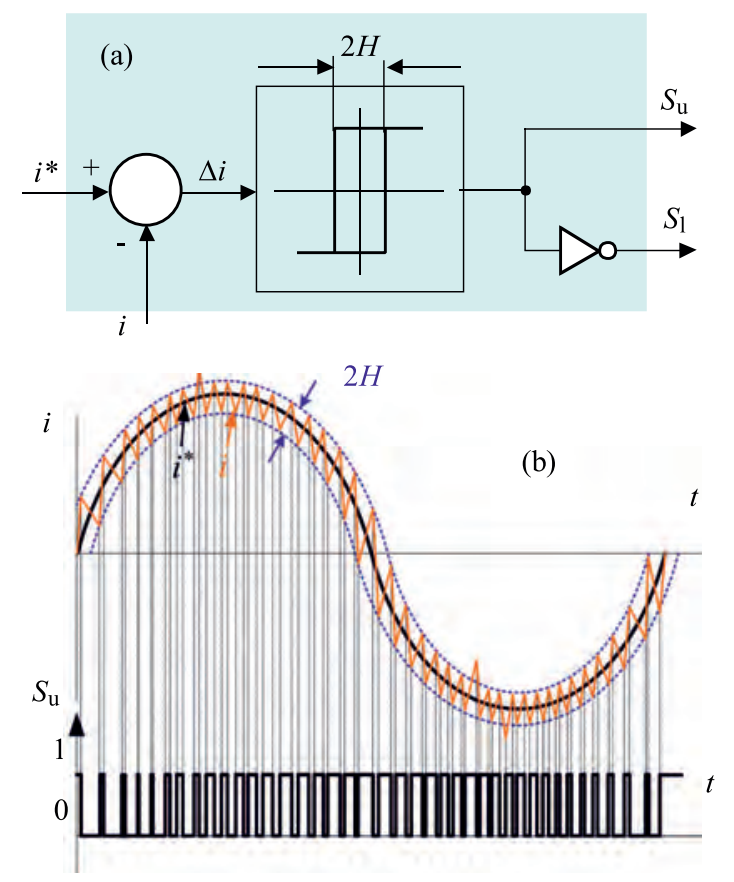

Fig. 3. Operating principle of the classical hysteresis current controller: (a) - hysteresis controller configuration and (b) - current waveforms and upper IGBT switching signals

ing the power converter losses under hysteresis switching, which is used in this investigation, was first presented in [27]. This method requires only knowledge of datasheet information of the IGBT module and three inputs, namely the dc-link voltage, the phase current and the gate switching signals of the upper IGBT in the converter phase leg. These inputs are easily accessible and can be determined either experimentally or through simulations. At the same time, the method does not require a complex IGBT-diode model, thermal measurements or detailed knowledge of physical characteristics, and is independent of the switching frequency. The method was validated by comparison to commercial software in [27] and with calorimetric measurements in [28]. It was shown that it has an average estimation error less than $8 \%$, in both periodic and aperiodic switching schemes, which is less than prior published estimation errors [14,26].

Considering the above, the objectives in this paper are first to calculate the power converter losses in the SEIG vector control system using the algorithm presented in [27] and [28], then to determine the dependency of the power converter losses on various control system's parameters and finally to use the calculated power converter losses for offline correction of the calculated system's efficiency. Thus obtained efficiency values are to be validated by comparison with the measured efficiency values.

\section{SEIG VECTOR CONTROL SYSTEM}

\subsection{Basic Features of the Control System}

The basic configuration of the SEIG vector control system under consideration is shown in Fig. 1, whereas the scheme of the indirect rotor-flux-oriented (IRFO) controller is shown in Fig. 2. The control system and the corresponding control algorithm are described and explained in detail in [7] so here are given only their basic features. The main components of the system are the induction generator, the prime mover, the three-phase power converter with IGBTs and free-wheeling diodes, the indirect rotor-flux-oriented (IRFO) controller and the dc link containing the exciting capacitor and resistive load. The dclink battery provides the initial voltage across the capacitor during the excitation process. As soon as the dc-link voltage rises to a value higher than the battery voltage, the battery is automatically switched off by means of a diode. In Fig. 1, $\omega_{r}, i_{s a}, i_{s b}, i_{s c}$ and $u_{d c}$ denote the rotor speed, the stator phase currents and the dc-link voltage, respectively, and represent the inputs to the IRFO controller (Fig. 2). The outputs of the IRFO controller are the gate switching signals for the power converter.

The IRFO control algorithm is responsible for keeping the dc-link voltage constant and equal to the reference value regardless of the changes in both the load and rotor speed. In the control system model, the copper and the iron losses of a SEIG are taken into account, while the power converter losses are neglected (ie the IGBTs and diodes are modeled as ideal switches). In [7], the proposed control system was verified both through simulations and experimentally. Among other it was shown that the corresponding model enables significantly more accurate estimation of the actual losses and efficiency compared to the conventional model. By application of the converter losses estimation algorithm reported in [27] and [28], the estimation accuracy of the overall system losses and thus efficiency could be further improved. This particular vector control system was chosen for the analysis not only because of its excellent control features and model accuracy but also because it involves hysteresis switching for keeping the stator phase currents under control.

\subsection{Hysteresis Current Control}

Figure 3 shows the basic operating principle of the current controller used in the considered control system. It is, in fact, the classical hysteresis current controller with a fixed hysteresis band. The control objective is to keep the actual phase current within the hysteresis band placed around the reference sinusoidal phase current, as shown in Fig. 3b.

The phase current error $\Delta i$, ie the difference between the reference phase current $i^{*}$ and the actual phase current $i$, represents the controller input signal whereas $H$ represents the specified fixed hysteresis band. If the current error $\Delta i$ is positive and equal to or greater than the hysteresis band $H$, the gate switching signals $S_{u}=1$ and $S_{l}=0$ are generated, thus leading to an increase in the phase current instantaneous value. Otherwise, if the current error $\Delta i$ is negative and equal to or greater than the hysteresis band $H$, the gate switching signals $S_{u}=0$ and $S_{l}=1$ are generated at the output, thus leading 
to a decrease in the phase current instantaneous value. Ideally, the stator current is always retained within the specified hysteresis band limits, while actually the current may temporarily cross the hysteresis band boundaries by a maximum margin of $H$ [29]. The hysteresis current control is relatively easy to implement and gives excellent results both in steady state and during transients. On the other side, it is characterized by variable and unpredictable switching frequency, which, among other things, makes the power converter losses more difficult to determine.

\section{POWER CONVERTER LOSS ESTIMATION}

\subsection{IGBT and Diode Power Losses under Hys- teresis Switching}

The power losses in semiconductor switches such as the IGBT or diode can be divided into conduction losses, switching losses (turn-on and turn-off) and blocking losses, where the latter are generally considered negligible. Hence, with IGBTs, turn-on, turn-off and conduction losses are considered, whereas with diodes, turn-on losses are neglected so only turn-off and conduction losses are considered. Total losses of the power converter under consideration equal the sum of individual losses in the IGBTs and diodes. However, it is a difficult task to determine these losses accurately because of their dependence on a number of parameters such as the switching frequency, the amplitude and frequency of the phase current, the dc-link voltage, the junction temperature, etc. In the case under consideration, determination of the power converter losses is made even more difficult by the variable and unpredictable switching frequency.

The interplay between the phase current error, the IGBT gate switching signals, the direction of the phase current and the power (energy) losses in an IGBT-diode pair is rather complex. For clarification, an example is given in Fig. 4. To further simplify the analysis, only one phase leg of the three-phase power converter is considered (phase a) and the IGBTs are replaced by switches. By convention, the phase current is assumed positive when flowing towards the SEIG.

In Fig. 4, $T_{1}$ and $T_{2}$ denote the upper and the lower IGBT in the phase leg, respectively, while $D_{1}$ and $D_{2}$ denote the corresponding free-wheeling diodes. $T_{1}$ and $D_{2}$ are responsible for conducting the positive current, while $T_{2}$ and $D_{1}$ are responsible for conducting the negative current. $T_{s}$ denotes the sampling time, while $k_{0}, k_{1}, \ldots, k_{8}$ denote the sampling instants. The phase current flow for the sample $k$ is indicated by a solid line with an arrow, whereas the phase current flow for the sample $k-1$ is indicated by a dashed line with an arrow. Note that only a small fraction of a current cycle is analyzed (total of eight sampling intervals). However, it covers all combinations that lead to an increase in the upper IGBT-diode power losses. By analogy, similar analysis could be applied to any other IGBT-diode pair of the three-phase power converter.

Figure $4 \mathrm{a}$ shows the first sampling interval, $k_{0}-k_{1}$. At $k_{0}$, the gate switching signal $S_{1}$ has changed from 1 to 0 (turn-off signal for the upper IGBT and turn-on signal for the lower IGBT) because the phase current error, $\Delta i=i_{a}^{*}-i_{a}$, reached the negative value equal to $H$. However, at the next sampling instant, $k_{1}$, the gate switching signal did not change because the actual phase current was within the hysteresis band limits. Since the actual phase current had a positive value at both sampling instants and $T_{1}$ has been turned off, the current could only flow through $D_{2}$, which consequently lead to a decrease in the phase current instantaneous value (the energy previously accumulated in the stator inductance $L_{S}$ was dissipated on the stator resistance $\left.R_{S}\right)$. Note, however, that within this sampling interval no power loss occurred in the upper IGBT-diode pair.

The second sampling interval, $k_{1}-k_{2}$, is shown in Fig. 4b. At $k_{1}$, the gate switching signal $S_{1}$ was 0 , while at $k_{2}$, the actual phase current reached the hysteresis band limit so $S_{1}$ changed from 0 to 1 (turn-on signal for the upper IGBT and turn-off signal for the lower IGBT). The phase current had a positive value at $k_{2}$ so $T_{1}$ turned on and started conducting. This required a certain amount of energy, ie the turn-on energy $E_{T, o n}$, which consequently lead to an increase in the $T_{1}$ switching losses (IGBT turn-on losses).

In Fig. 4c, it can be seen that at the end of the third sampling interval $\left(k_{3}\right)$, the gate switching signal remained equal to 1 because the actual phase current remained within the hysteresis band limits. In addition, because the current retained the positive value, $T_{1}$ was conducting during this interval, which consequently lead to an increase in the $T_{1}$ conduction losses $\left(E_{T, \text { cond }}\right)$.

At $k_{4}$, the actual phase current reached the hysteresis band limit so the gate switching signal changed from 1 to 0 , turning $T_{1}$ off. This required the turn-off energy $E_{T, \text { off }}$, which consequently lead to an increase in the $T_{1}$ switching losses (IGBT turn-off losses). Because the actual phase current had a positive value at $k_{4}, D_{2}$ started conducting (Fig. 4d).

Between $k_{4}$ and $k_{5}$, the phase current reversed direction and started flowing towards the converter. Because the actual phase current remained within the hysteresis band limits, there was no change in the gate switching signal and the current was taken by $T_{2}$ (Fig. 4e). The current commutation from a diode to an IGBT while the corresponding IGBT gate is high causes a negligible switching effect because the voltage across the IGBT or diode is low compared to the dc-link voltage. Regardless, within this sampling interval no power loss occurred in the upper IGBT-diode pair.

At $k_{6}$, the gate switching signal changed from 0 to 1 . Because $T_{1}$ cannot conduct during the negative current half-cycle, $D_{1}$ turned on and started conducting (Fig. 4f). 

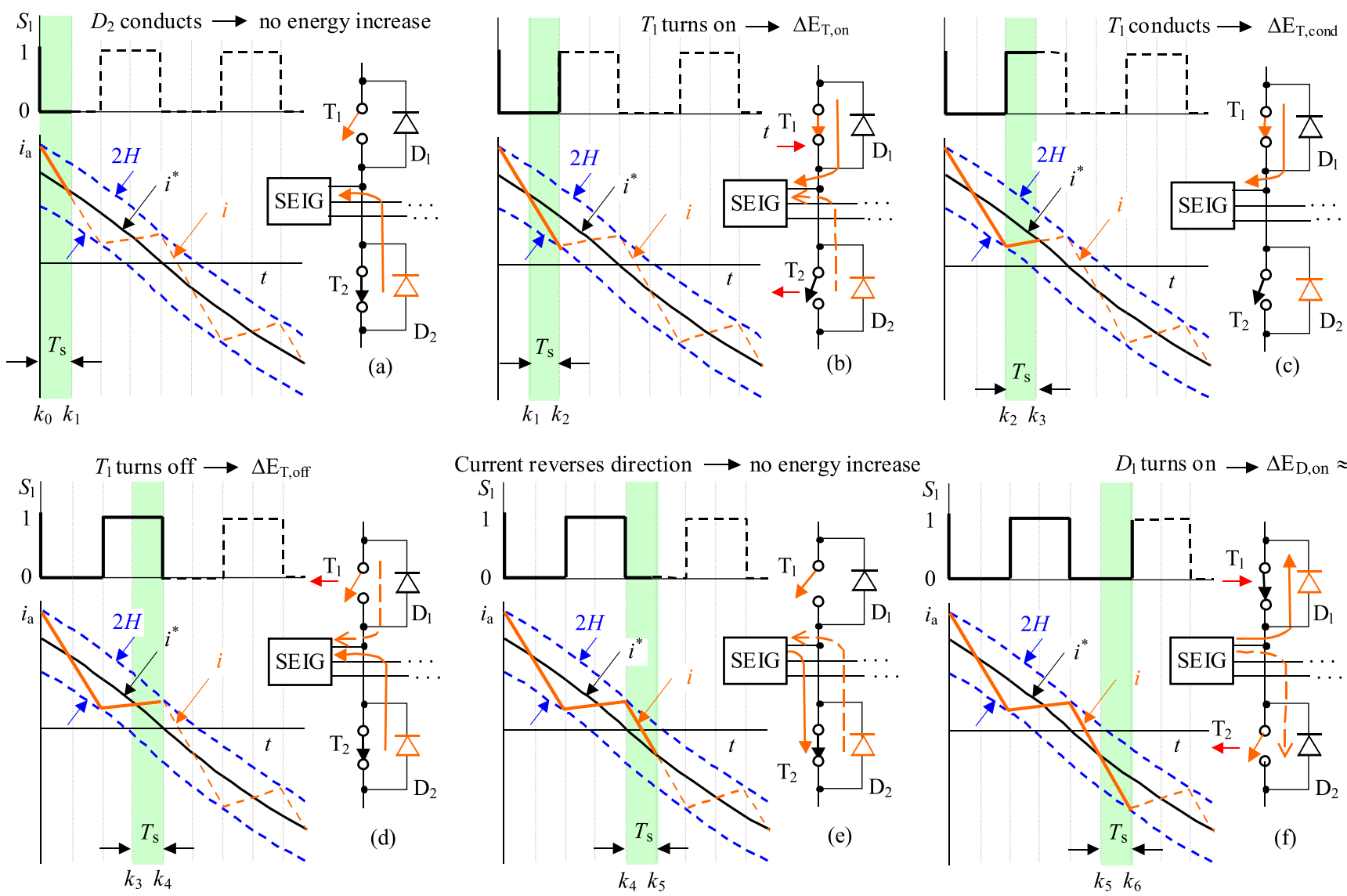

$k_{2} k_{3}$
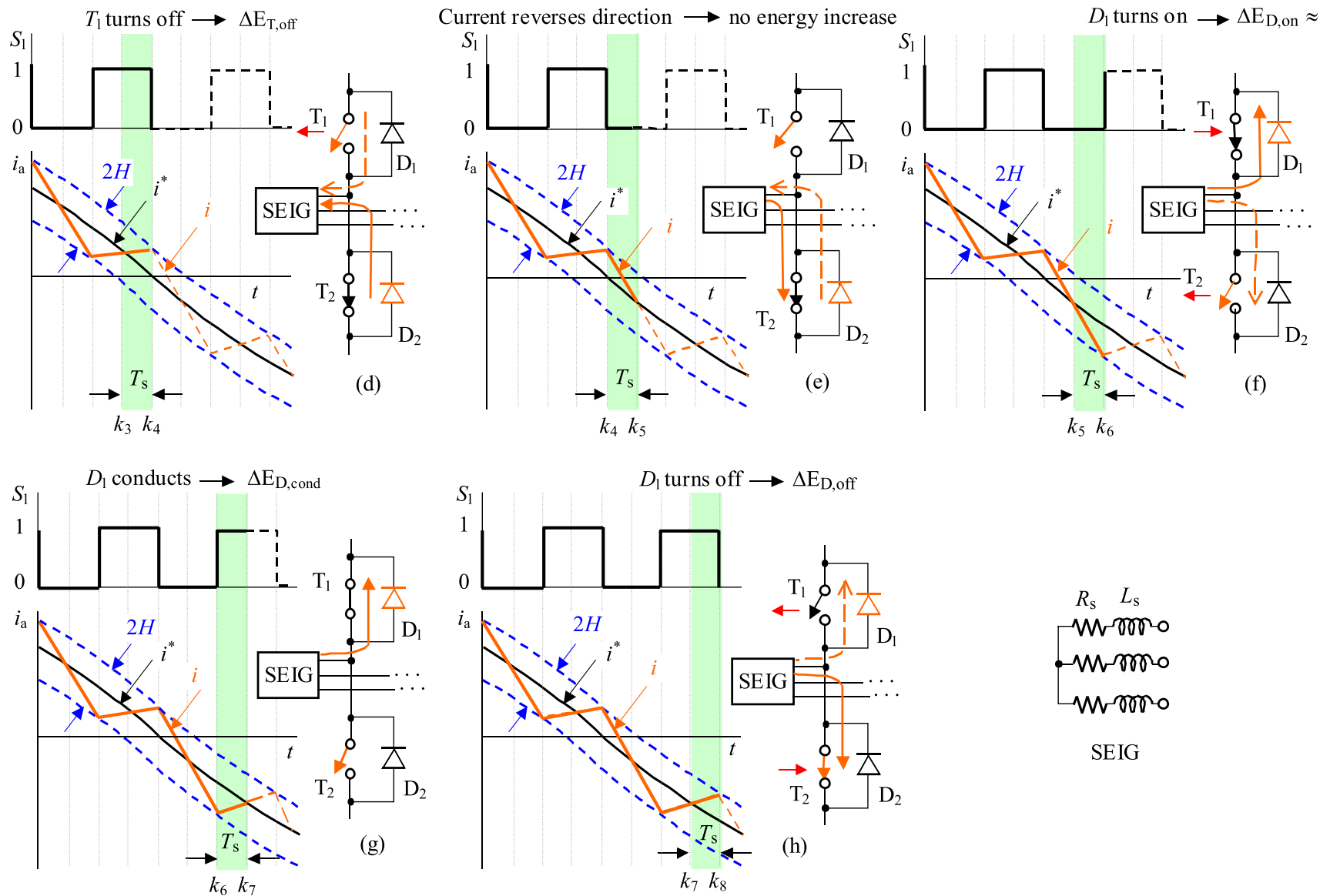

Fig. 4. Example of interaction between IGBT gate switching signals, reference and actual phase current values and upper IGBT-diode power (energy) losses

However, the diode turn-on losses are considered negligible so there was no increase in the upper IGBT-diode pair power losses during this sampling interval.

At $k_{7}$, the phase current was still within the hysteresis band limits so the gate switching signal remained unchanged. Because the current had a negative value both at $k_{6}$ and $k_{7}, D_{1}$ was conducting during this interval (Fig. $4 \mathrm{~g}$ ) so there was an increase in the $D_{1}$ conduction losses $\left(E_{D, \text { cond }}\right)$.

Finally at $k_{8}$, the actual phase current hit the upper hysteresis band limit, which caused the gate switching signal to change from 1 to 0 . The current had a nega- tive value at $k_{8}$, so $D_{1}$ turned off and the current was taken by $T_{2}$ (Fig. $4 \mathrm{~h}$ ). This required the turn-off energy $E_{D, o f f}$, which consequently lead to an increase in the $D_{1}$ switching losses (diode turn-off losses).

\subsection{Algorithm for Power Converter Loss Esti- mation}

The conditions regarding the phase current direction, the upper IGBT gate switching signal and the upper IGBT-diode pair operating state which are related to an increase in the upper IGBT-diode power losses are 
summarized in Table 1 (open circuits, short circuits and fault conditions are not considered).

Table 1. Power loss conditions for the upper IGBT-diode pair

\begin{tabular}{lll}
\hline $\begin{array}{l}\text { current } \\
\text { direction }\end{array}$ & $\begin{array}{l}\text { gate switching } \\
\text { signal }\end{array}$ & $\begin{array}{l}\text { IGBT-diode } \\
\text { operating } \\
\text { state }\end{array}$ \\
\hline$I(k) \geq 0$ & $\mathrm{~S}(\mathrm{k}-1)=0 \& \mathrm{~S}(\mathrm{k})=1$ & IGBT turns on \\
$I(k-1) \geq 0$ & $\mathrm{~S}(\mathrm{k}-1)=1 \& \mathrm{~S}(\mathrm{k})=0$ & IGBT turns off \\
$I(k-1) \geq 0 \& I(k) \geq 0$ & $\mathrm{~S}(\mathrm{k}-1)=1 \& \mathrm{~S}(\mathrm{k})=1$ & IGBT conducts \\
$I(k-1)<0$ & $\mathrm{~S}(\mathrm{k}-1)=1 \& \mathrm{~S}(\mathrm{k})=0$ & Diode turns off \\
$I(k-1)<0 \& I(k)<0$ & $\mathrm{~S}(\mathrm{k}-1)=1 \& \mathrm{~S}(\mathrm{k})=1$ & Diode conducts \\
\hline
\end{tabular}

The loss estimation algorithm used in this paper is based on recognizing the power loss conditions shown in Table 1 . The algorithm relies on the following three inputs: dc-link voltage, phase current and gate switching signals. In the IRFO control system under consideration, all three required inputs are easily accessible. In fact, the IRFO control algorithm itself requires measurement of the phase currents and dc-link voltage so application of the loss estimation algorithm does not require any additional sensors to be installed. Besides the three inputs, the loss estimation algorithm requires only knowledge of the available datasheet information of the IGBT module. In particular, it requires at least four or five points to be taken from datasheet graphs in order to approximate the switching and conduction energies of the IGBT and the diode in the form of polynomial functions. Switching energies are additionally scaled with respect to the actual dc-link voltage. Although the loss estimation algorithm does not account for power losses dependency on the junction temperature $T_{j}$, this temperature is usually given as a parameter in datasheet graphs so it would be more correct to say that the algorithm assumes $T_{j}$ as independent of the actual operating conditions. In datasheet graphs of the IGBT module SKM 100GB125DN, manufactured by Semikron [30], the conduction energies are defined for two different junction temperatures, ie $T_{j}=25^{\circ} \mathrm{C}$ and $T_{j}=125^{\circ} \mathrm{C}$, while the switching energies are defined only for $T_{j}=125^{\circ} \mathrm{C}$. Hence, the latter value has to be used for estimation of both switching and conduction energies. The datasheet graphs are approximated with secondorder polynomials whereas the corresponding coefficients are determined using the MATLAB's curve fitting function. The values of the polynomial coefficients are given in Appendix A. In equations (1)-(5), $E_{T, o n}, E_{T, \text { off }}$ and $E_{T, \text { cond }}$ represent the IGBT turn-on, turn-off and conduction energies, respectively, whereas $E_{D, \text { off }}$ and $E_{D, \text { cond }}$ represent the diode turn-off and conduction energies, respectively. $U_{C E}$ and $I_{C}$ are the IGBT's collector-emitter voltage and collector current, respectively, whereas $U_{D}$ and $I_{D}$ are the diode's forward voltage and current, respectively. The initial values of $E_{T, o n}, E_{T, o f f}, E_{T, c o n d}$,
$E_{D, \text { off }}$ and $E_{D, c o n d}$ are set to zero.

$$
\begin{gathered}
E_{T, \text { on }}(k)=E_{T, \text { on }}(k-1)+a_{1} I_{C}^{2}(k)+a_{2}\left|I_{C}(k)\right|+a_{3}, \\
E_{T, \text { off }}(k)=E_{T, \text { off }}(k-1)+b_{1} I_{C}^{2}(k)+b_{2}\left|I_{C}(k)\right|+b_{3}, \\
E_{D, o f f}(k)=E_{D, o f f}(k-1)+c_{1} I_{D}^{2}(k)+c_{2}\left|I_{D}(k)\right|+c_{3}, \\
E_{T, \text { cond }}(k)=E_{T, \text { cond }}(k-1)+ \\
U_{C E}(k)\left|I_{C}(k)\right|[t(k)-t(k-1)] \\
U_{C E}(k)=d_{1} I_{C}^{2}(k)+d_{2}\left|I_{C}(k)\right|+d_{3}, \\
E_{D, \text { cond }}(k)=E_{D, \text { cond }}(k-1)+ \\
U_{D}(k)\left|I_{D}(k)\right|[t(k)-t(k-1)] \\
U_{D}(k)=e_{1} I_{D}^{2}(k)+e_{2}\left|I_{D}(k)\right|+e_{3} .
\end{gathered}
$$

The proposed loss estimation method detects the IGBT and diode operating states based on the phase current direction and gate switching signal both at the current and previous sampling instant (Table 1). In this paper, the inputs for the algorithm are determined by simulations in the MATLAB Simulink environment so the sampling rate of the algorithm equals the sampling time of the control system model, ie $k T_{s}-(k-1) T_{s}=$ $T_{s}=1 / 28000 \mathrm{~s}$. By this, the actual current is assumed constant during one sampling interval, which is a reasonable assumption considering the low sampling time value. The maximum converter's switching frequency is equal to $1 /\left(2 T_{s}\right)=14 \mathrm{kHz}$. The total power losses of the considered IGBT-diode pair are obtained by summing the individual energies in equations (1)-(5) accumulated during the selected time window (eg few cycles of the phase current) and dividing the result by the time window. To obtain the total losses of the power converter, the total power losses of the IGBT-diode pair are multiplied by a factor of six since there are six such pairs in the considered three-phase power converter.

\section{RESULTS AND DISCUSSION}

The simulation results are obtained by using the Simulink model of the IRFO control system shown in Figures 1 and 2, whereas the experimental results are obtained by using the control system's laboratory setup. The induction generator with the power rating of $1.5 \mathrm{~kW}$ and with the rated stator phase current equal to $3.81 \mathrm{~A}$ is used for the analysis (other parameters of the induction generator are given in Appendix B). The experimental power converter consists of three IGBT modules SKM 100GB125DN and hybrid dual IGBT drivers SKHI 22B, manufactured by Semikron [31]. A more detailed description of both the Simulink model and the laboratory setup can be found in [7].

Figure 5 shows an example of energy increments in the upper IGBT-diode pair during one cycle of the simulated phase current, along with the corresponding phase current waveforms and gate switching signals. The results 


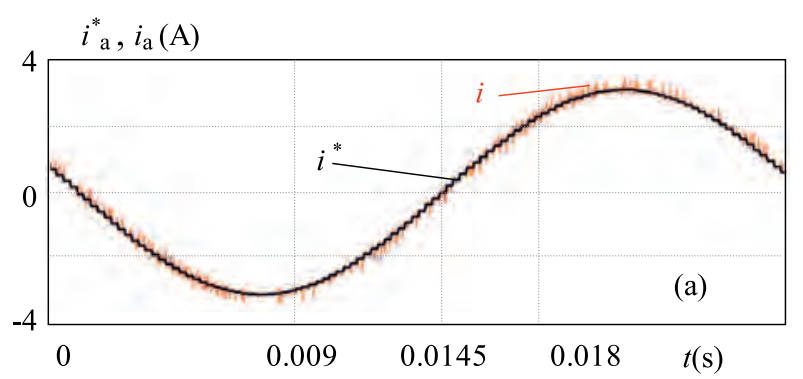

IGBT-diode energies ( $\mathrm{J}$ ) and gate switching signals

(b)

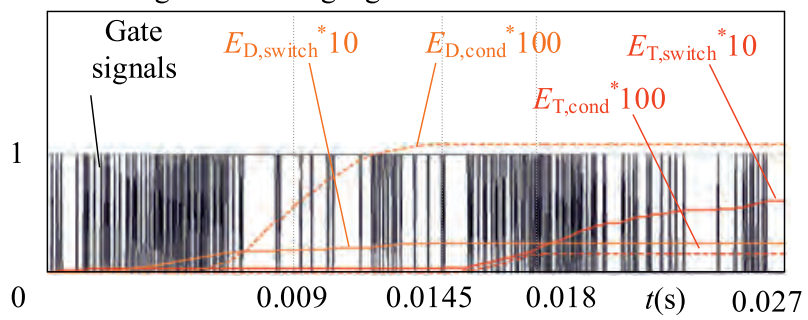

Fig. 5. Simulation phase current waveforms, gate switching signals and energy increments during one phase current cycle for the upper IGBT-diode pair

IGBT-diode conduction losses (W)

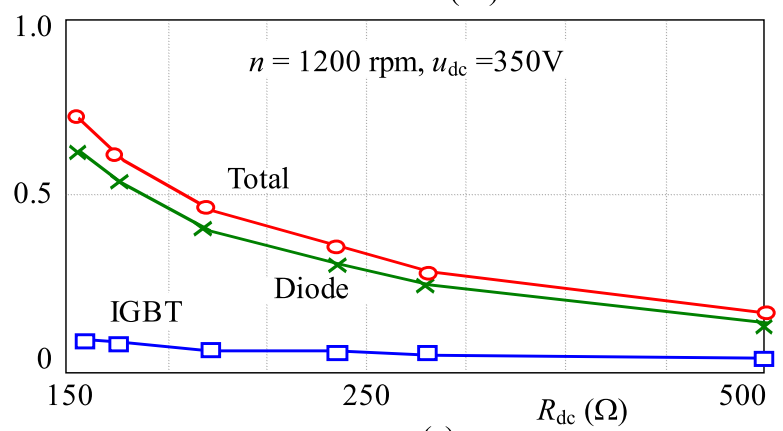

(a)

IGBT-diode switching losses (W)

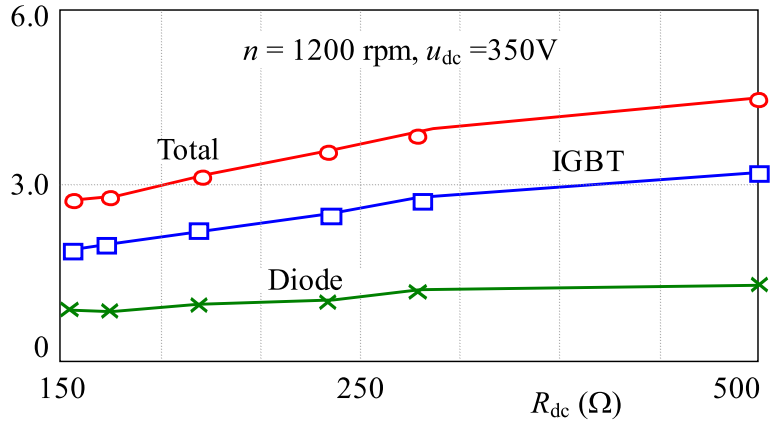

(b)

Fig. 6. Upper IGBT-diode power losses as a function of load resistance (simulations): (a) - - switching losses and (b) - conduction losses

are obtained for the following parameters: $n=1200 \mathrm{rpm}$, $u_{d c}=350 \mathrm{~V}, R_{d c}=220 \Omega$ and $H=0.1 \mathrm{~A}$.

In Fig. 5, during the negative half-cycle, the IGBT switching and conduction energies remain unchanged. However, during the positive half-cycle, there is a notable increase in these energies. Namely, a change in the gate switching signal value leads either to an increase in the IGBT turn-on energy or to an increase in the IGBT turn-off energy, depending on whether the gate switching signal changes from 0 to 1 or the other way around. This increase more substantial when the gate switching signal value changes more frequently. When the gate switching signal is equal to 1 , there is an increase in the IGBT conduction energy. Otherwise, when it is equal to 0 , there is no increase in the IGBT conduction energy.

Similarly, diode turn-off and conduction energies remain unchanged during the positive half-cycle, while there is a notable increase in these energies during the negative half-cycle, again depending on the gate switching signal value.

Figure 6 shows the upper IGBT-diode switching and conduction power losses as a function of the load resistance value (ie, the load current). The results are obtained by simulations for the following parameters: $n=1200 \mathrm{rpm}, u_{d c}=350 \mathrm{~V}$ and $H=0.1 \mathrm{~A}$. The time window equal to 8 cycles of the phase current is used for calculation of the IGBT-diode losses.

Based on the results shown in Fig. 6a it can be concluded that by increasing the load current (ie, by decreasing the load resistance), both the IGBT and diode conduction losses are increased. It is understandably so because when the load current is increased the current flowing through the semiconductor switches is also increased and so are the corresponding conduction losses. On the other hand, the IGBT and diode switching losses are decreased by increasing the load current, which suggests a decrease in the switching frequency. For the considered load resistance values, the total switching losses are dominant, especially for high load resistance values. For example, at $R_{d c}=500 \Omega$, the switching losses are about 28 times greater than the conduction losses, while at $R_{d c}=155 \Omega$, they are only about 4 times greater. This switching losses dominance is partly explained by the relatively high value of the dc-link voltage since they are scaled with respect to the dc-link voltage. Consequently, by decreasing the load resistance value, the sum of the switching and conduction losses in the IGBT-diode pair, as well as in the whole power converter, decreases for the case under consideration. Here it has to be noted that due to its variability and unpredictability, the switching frequency could not be considered as a parameter in the presented analysis.

Using the loss estimation algorithm, the total losses of the power converter are calculated over the following ranges of the rotor speed, dc-link voltage and load resistance: $n=900-1500 \mathrm{rpm}, u_{d c}=200-350 \mathrm{~V}$ and $R_{d c}=110-500 \Omega$.

The obtained results are shown in Fig. 7 where it can be seen that the power converter losses are proportional to the voltage for constant rotor speed, while they are inversely proportional to the rotor speed for constant dclink voltage. Also, there is no significant variation in the power converter losses with respect to the load resistance for constant rotor speed and dc-link voltage, which is 
Power converter losses (W)

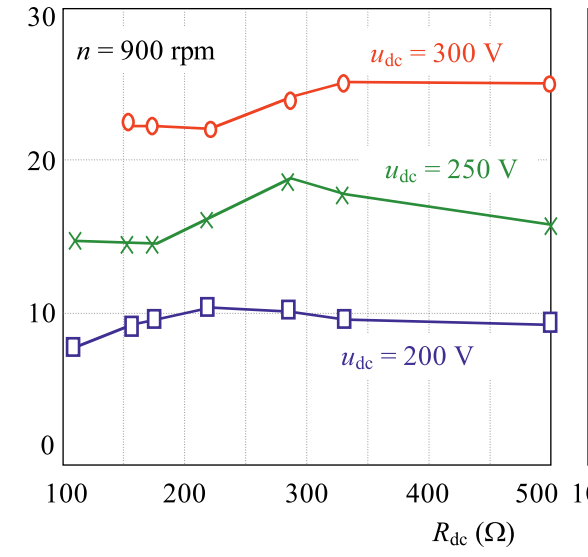

(a)

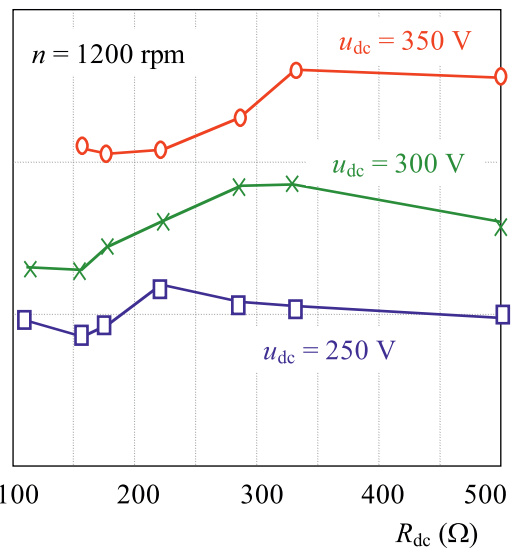

(b)

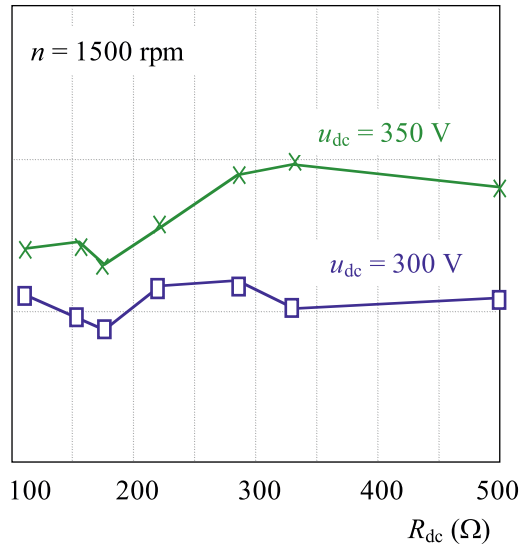

(c)

Fig. 7. Total power converter losses as a function of load resistance (simulations): (a) $-n=900 \mathrm{rpm}$, (b) $-n=1200 \mathrm{rpm}$ and (c) $-n=1500 \mathrm{rpm}$

Maximum effeciency (\%)

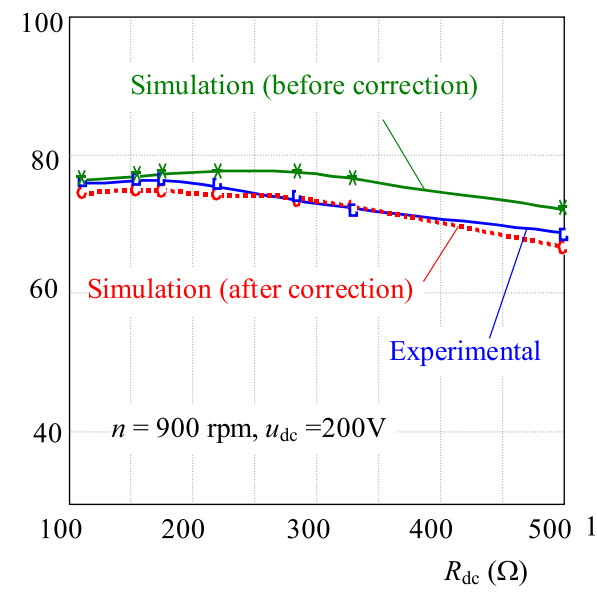

(a)

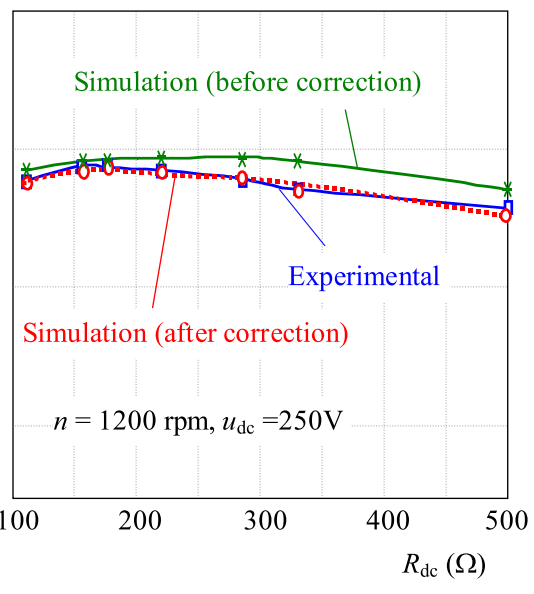

(b)

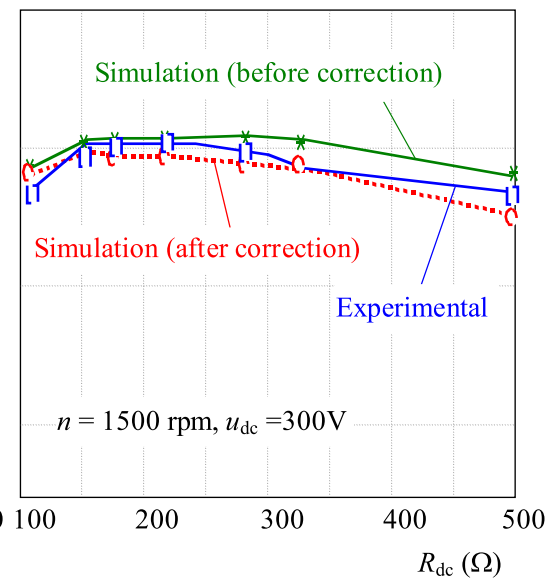

(c)

Fig. 8. Maximum efficiency curves obtained at: (a) $-n=900 \mathrm{rpm}, u_{d c}=200 \mathrm{~V},(\mathrm{~b})-n=1200 \mathrm{rpm}, u_{d c}=250 \mathrm{~V}$, and $(\mathrm{c})-$ $n=1500 \mathrm{rpm}, u_{d c}=300 \mathrm{~V}$

most likely due to the fact that any change in the load resistance causes changes in the switching losses and in the conduction losses which cancel each other out (Fig. 6). However, the power converter losses are proportional to the voltage for constant rotor speed and load resistance value. This is explained by the fact that the switching losses are proportional to the dc-link voltage (factor $k_{u}$ in Appendix A), whereas the conduction losses are proportional to the load current, ie to the dc-link voltage for constant load resistance value. Hence, increasing the dclink voltage while keeping the load resistance unchanged leads to an increase in both power loss components.

Finally, the calculated power converter losses are used for correction of the IRFO control system maximum efficiency curves obtained by using the corresponding Simulink model, described in [7], in which the power converter is assumed ideal.

The maximum efficiency curves are obtained by setting the induction generator magnetizing flux to an optimum value for each of the considered operating regimes. This means, without going into details, that the flux factor $k_{\psi}$, shown in Fig. 2, had to be manually adjusted for each considered regime. For validation purposes, both the uncorrected and corrected maximum efficiency curves are compared with the experimental curves and the results are shown in Fig. 8.

It can be seen that the corrected maximum efficiency curves very well represent the experimental curves. However, while it is normal to expect the corrected curves to be placed slightly above the experimental curves, thus leaving enough space for the stray and mechanical losses if they were to be considered, it seems that in some cases small parts of the corrected curves are placed slightly below the experimental ones. This indicates at the possibility of overestimation of the power converter losses. The overestimation of the power converter losses can be partly due to the fact that the actual semiconductor junction temperature is in most cases significantly lower than the one assumed in the loss estimation algorithm, which is in fact only $25^{\circ} \mathrm{C}$ lower than the maximum junc- 
tion temperature defined in the IGBT module datasheet $\left(T_{\text {jmax }}=150^{\circ} \mathrm{C}\right)$. Higher assumed value of the junction temperature means higher assumed power converter losses. Besides this, the accuracy of the loss estimation algorithm also depends on the accuracy of extraction of the necessary data points from the datasheet as well as on the accuracy of the datasheet graphs.

Similar results were obtained for other combinations of the rotor speed and dc-link voltage within the considered respective scopes, ie $n=900-1500 \mathrm{rpm}$ and $u_{d c}=200-350 \mathrm{~V}$.

\section{CONCLUSIONS}

The proposed approach provides highly accurate estimation of the maximum achievable system's efficiency over wide ranges of rotor speed, dc-link voltage and load resistance for the case of a vector controlled SEIG. It also provides insight into power converter losses dependency on various control system parameters. The case analyzed in this paper addresses hysteresis switching but the analysis could be easily extended to periodic switching schemes. The considered loss estimation algorithm is fairly easy to implement, can be used for both periodic and aperiodic switching schemes, and has the reported average estimation error less than $8 \%$. The obtained results show that the power converter losses have a higher contribution to the overall system's losses when the SEIG is lightly loaded and, consequently, in such cases they have a greater impact on the overall system's efficiency. It is shown that this impact can be far from negligible, so in order to obtain an accurate approximation of the actual system's losses or efficiency it is mandatory to account for the power converter losses.

\section{Appendix A}

Polynomial coefficients in equations (1)-(5)

$$
\begin{array}{lll}
a_{1}=0, & a_{2}=0.1265 k_{u}, & a_{3}=0.637 k_{u}, \\
b_{1}=0, & b_{2}=0.0461 k_{u}, & b_{3}=0.539 k_{u}, \\
c_{1}=0, & c_{2}=0.0477 k_{u}, & c_{3}=0.591 k_{u}, \\
d_{1}=-0.012421, & d_{2}=0.24562, & d_{3}=0.54143, \\
e_{1}=-0.0080535, & e_{2}=0.1176, & e_{3}=0.4652 .
\end{array}
$$

where $k_{u}$ is the scaling factor equal to dc-link voltage to datasheet dc voltage ratio, ie $k_{u}=U_{d c} / U_{C C}$.

$a_{1}, b_{1}$ and $c_{1}$ are set equal to zero because the corresponding datasheet functions can be considered linear in the area of interest ( $i e$, for currents less than $10 \mathrm{~A}$ ).

\section{Appendix B}

Induction generator parameters

$P_{n}=1.5 \mathrm{~kW}, U_{n}=380 \mathrm{~V}, p=2, Y, I_{n}=3.81 \mathrm{~A}$, $n_{n}=1391 \mathrm{rpm}, L_{m}^{n}=0.4058 \mathrm{H}, L_{s \sigma}=0.01823 \mathrm{H}$, $L_{r \sigma}=0.02185 \mathrm{H}, R_{s}=4.293 \Omega\left(\right.$ at $\left.20^{\circ} \mathrm{C}\right)$,
$R_{r}=3.866 \Omega\left(\right.$ at $\left.20^{\circ} \mathrm{C}\right), T_{n}=10.5 \mathrm{Nm}$,

$J=0.0071 \mathrm{kgm}^{2}, \Psi_{r n}=0.845 \mathrm{~Wb}, \eta=78 \%$.

\section{REFERENCES}

[1] SINGH, G. K.: Self-Excited Induction Generator Research a Survey, Electric Power Systems Research 69 No. 2-3 (2004), $107-114$.

[2] Simoes, M. G.-CHAKRABORTY, S.-WOOD, R.: Induction Generators for Small Wind Energy Systems, IEEE Power Electronics Society Newsletter (2006), 19-23..

[3] WAGNER, C.: Self-Excitation of Induction Motors, AIEE Transactions on Electrical Engineering 58 No. 2 (1939), 47-51.

[4] BASSET, E. D.-POTTER, F. M. : Capacitive Excitation for Induction Generators, AIEE Transactions on Electrical Engineering 54 No. 5 (1935), 540-545.

[5] BAŠIĆ, M.-VUKADINOVIĆ, D.-LUKAČ, D. : Novel Dynamic Model of Self-Excited Induction Generator with Iron Losses, International Journal of Mathematical Models and Methods in Applied Sciences 5 No. 2 (2011), 221-229.

[6] BAŠIĆ, M.-VUKADINOVIĆ, D.-PETROVIĆ, G. : Dynamic and Pole-Zero Analysis of Self-Excited Induction Generator using a Novel Model with Iron Losses, International Journal of Electrical Power \& Energy Systems 42 No. 1 (2012), 105-118.

[7] BAŠIĆ, M.-VUKADINOVIĆ, D.: Vector Control System of a Self-Excited Induction Generator Including Iron Losses and Magnetic Saturation, Control Engineering Practice 21 No. 4 (2013), 395-406.

[8] LEVI, E.-LAMine, A.-CAVAGNiNO, A. : Rotor-Flux-Oriented Control of Induction Machines Considering the Stray Load Losses, Proc. IEEE PESC'05, 2005, pp. 1325-1331.

[9] BOLDEA, I.-NASER, S.: The Induction Machine Handbook, CRC Press LCC, Boca Raton (Florida), 2002.

10] BerRinger, K.-MARVin, J.-PERruchoud, P. : Semiconductor Power Losses in AC Inverters, Proc. IEEE IAS'95, 1995, pp. 882-888.

[11] BIERHOFF, M. H.-FUCHS, F. W.: Semiconductor Losses in Voltage Source and Current Source IGBT Converters based on Analytical Derivation, Proc. IEEE PESC '04 2004, pp. 2836-2842.

[12] KUROKAWA, M.-KONISHI, Y.-IWAMOTO, H.-NAKAOKA, M.: Power Loss Estimations of Voltage Source ThreePhase Soft Switching Inverter with Resonant DC Link Assisted Lossless Snubber Capacitor, Proc. IEEE IECON'00, 2000, pp. 350-355.

[13] KUTKUT, N. H.-Divan, D. M.-NOVOTNY, D. W.-MARION, R. H.: Design Considerations and Topology Selection for a 120-kW IGBT Converter for EV Fast Charging, IEEE Transactions on Power Electronics 13 No. 1 (1998), 169-178.

[14] CONSOLI, A.-LICITRA, C.-MUSUMECI, S.-TESTA, A. -FRISINA, F.-LETOR, R.: Comparative Investigation on Power Losses in Soft-Switching Insulated Gate Devices, Proc. IEEE ISPSD'94, 1994, pp. 87-92.

[15] SCHWARZER, U.-De DONCKER, R. W.: Power Losses of IGBTs in an Inverter Prototype for High Frequency Inductive Heating Applications, Proc. IEEE IECON'01, 2001, pp. 793-798.

[16] ISHIKO, M.-KONDO, T.: A Simple Approach for Dynamic Junction Temperature Estimation of IGBTs on PWM Operating Conditions, Proc. IEEE PESC'07, 2007, pp. 916-920.

[17] MURDoCK, D. A.-TORRES, J. E. R.-CONNORS, J. J.LORENZ, R. D. : Active Thermal Control of Power Electronic Modules, IEEE Transactions on Industry Applications 42 No. 2 (2006), 552-558. 
[18] LAKHSASI, A.-HAMRI, Y.-SKOREK, A. : Partially Coupled Electro-Thermal Analysis for Accurate Prediction of Switching Devices, Proc. IEEE Canadian Conference on Electrical and Computer Engineering, 2001, pp. 375-380.

[19] ABRAHAM, L.-REDDIG, M. : Determination of Switching Losses in IG-BTs by Loss-Summation-Method, Proc. IEEE IAS'95, 1995, pp. 1061-1068.

[20] BLAABJERG, F.-PEDERSEN, J. K.-SIGURJONSSON, S. -ELKJAER, A.: An Extended Model of Power Losses in Hard-Switched IGBT-Inverters, Proc. IEEE IAS'96 1996, pp. 1454-1463.

[21] YANQUN, S.-YAN, X.-JIAN, J.-YAN, D.-XIANGNING, H.-ZHAOHUI, Z.: Switching Loss Analysis and Modeling of Power Semiconductor Devices based on an Automatic Measurement System, Proc. IEEE International Symposium on Industrial Electronics, 2006, pp. 853-858.

[22] KIMBALL, J. W.: Modeling Controlled Switches and Diodes for Electro-Thermal Simulationinbook Proc. IEEE PESC'05.

[23] KOURO, S.-PEREZ, M.-ROBLES, H.-RODRIGUEZ, J. : Switching Loss Analysis of Modulation Methods used in Cascaded H-Bridge Multilevel Converters, Proc. IEEE PESC'08, 2008, pp. 4662-4668.

[24] CASSIMERE, B.-SUDHOFF, S. D.-ALIPRANTIS, D. C.SWINNEY, M. D.: IGBT and PN Junction Diode Loss Modeling for System Simulations, Proc. IEEE IEMDC'05, 2005, pp. 941-949.

[25] DROFENIK, U.-KOLAR, J. : A General Scheme for Calculating Switching and Conduction-Losses of Power Semiconductors in Numerical Circuit Simulations of Power Electronic Systems, Proc. IPEC'05, 2005.

[26] DEWEI, X.-HAIWEI, L.-LIPEI, H.-AZUMA, S.-KIMATA, M.-UCHIDA, R. : Power Loss and Junction Temperature Analysis of Power Semiconductor Devices, IEEE Transactions on Industry Applications 38 No. 5 (2002), 1426-1431.

[27] BAZZI, A. M.-KIMBALL, J. W.-KEPLEY, K.-KREIN, P. T. : TILAS: A Simple Analysis Tool for Estimating Power Losses in an IGBT-Diode Pair under Hysteresis Control in Three-Phase Inverters, Proc. IEEE APEC'09, 2009, pp. 637-641.

[28] BAZZI, A. M.-KREIN, P. T.-KIMBALL, J. W.-KEPLEY, K. : IGBT and Diode Loss Estimation under Hysteresis Switching, IEEE Transactions on Power Electronics 27 No. 3 (2012), 1044-1048.

[29] LOREnZ, R. D.-LIPO, D.-NOWOTNY, D. W. : Power Electronics and Variable Frequency Drives (Bose, B.K., ed.), IEEE Press, New York, 1997.

[30] Ultra-fast IGBT module SKM 100GB125DN, Semikron http://www.semikron.com/products/data/cur/assets/ SKM100GB125DN_SEMITRANS_2NI_21915390.pdf.

[31] Hybrid Dual IGBT Driver SKHI 22B, Semikron http://www.semikron.com/products/data/cur/assets/ SKHI_22_A_B_R_L5012521.pdf
Received 14 March 2013

Mateo Bašić was born in Split, Croatia, in 1982. He received the $\mathrm{BE}$ degree and the $\mathrm{PhD}$ degree, both in Electrical Engineering, from the University of Split, Croatia, respectively in 2006 and 2013. In 2008, he joined the University of Split, Faculty of Electrical Engineering, Mechanical Engineering and Naval Architecture, Department of Electric Power Engineering, as an assistant. His current research interests include selfexcited induction generators, induction machine control systems, power electronics and artificial intelligence. He has published one book and more than ten papers in scientific journals and conferences.

Dinko Vukadinović was born in Banja Luka, Bosnia and Herzegovina, in 1973. He received the BE degree from the University of Split, the ME degree from the University of Zagreb and the $\mathrm{PhD}$ degree from the University of Split, Croatia, in 1997, 2002 and 2005, respectively, all in electrical engineering. In 1998, he joined the University of Split, Faculty of Electrical Engineering, Mechanical Engineering and Naval Architecture (FESB), Department of Electric Power Engineering as a junior researcher. In 2013, he became a Full Professor at the University of Split. In 2009, he was appointed Chair of Power Electronics and Control at the University of Split, FESB. He is an Associate Editor of the Journal of Computer Science, Informatics and Electrical Engineering, and a member of the Editorial board of the Journal of Convergence Information Technology, Electrical and Electronic Engineering and International Journal of Innovative Research \& Development. His current research interests include induction machine control systems, power electronics, digital signal processors and artificial intelligence. He has published one book and more than 20 papers in scientific journals and conferences. Also, he was the editor of two books published by Nova Science Publishers Inc.

Miljenko Polić was born in Split, Croatia, in 1987. In 2011, he received the BE degree in Electrical Engineering from the University of Split, Croatia. In 2013, he joined the University of Split, Faculty of Electrical Engineering, Mechanical Engineering and Naval Architecture, Department of Electric Power Engineering, as an assistant. He is currently pursuing a $\mathrm{PhD}$ in Electrical Engineering at the University of Split, Croatia. His research interests include induction machine control systems and power electronics. He has published one paper in a scientific journal, one paper in international conference proceedings and one professional paper at a domestic symposium.

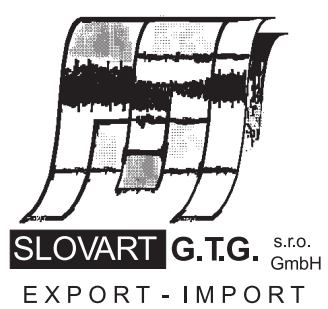

EXPORT - IMPORT
E X P OR T - I M P OR T

of periodicals and of non-periodically printed matters, books and CD-ROMs

Krupinská 4 PO BOX 152, 85299 Bratislava 5, Slovakia tel: ++421 263839 472-3, fax: ++421263839485 info@slovart-gtg.sk; http://www.slovart-gtg.sk

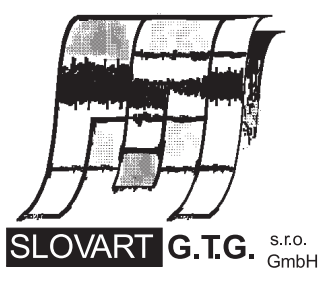

EXPORT - IMPORT 